\title{
Identifying transit deserts in major Texas cities where the supplies missed the demands
}

\author{
Junfeng Jiao \\ The University of Texas at Austin \\ jjiao@austin.utexas.edu
}

\begin{abstract}
Coined by the author, the concept "transit desert" is developed from the now common concept of a "food desert," which is an area where there is limited or no access to fresh food (Clark et al. 2002; Jiao et al. 2012; Whelan et al. 2002; Wrigley 1993; Wrigley et al. 2002). The food desert concept has received a lot of attention and influenced planning policies and practices. By applying the same idea to transit systems within urban areas, geographic areas can be identified where there is a lack of transit service. This involves identifying the transit dependent populations as a measure of transit demand, calculating the transit supply, and then subtracting the supply from the demand to measure the gap (Jiao \& Dillivan 2013). In detail, transit dependent populations are those who might require transit service to get around more than other people. The transit supply is measured by aggregating a number of criteria that contribute to better transit access and measured within a designated geographic area. Transit deserts are defined as areas where the transit demand is significantly greater than the supply.
\end{abstract}

\section{Article history:}

Received: March 10, 2016

Received in revised form: May 10,2016

Accepted: August 17, 2016

Available online: January 12,

2017

\section{Introduction}

Coined by the author, the concept "transit desert" is developed from the now common concept of a "food desert" (Clarke et al., 2002; Jiao et al., 2012; Whelan et al., 2002; Wrigley, 1993; Wrigley et al., 2002). By applying the same idea to urban transit systems, geographic areas with high transit demand but low transit service are named as "transit deserts." Locating transit deserts within cities involves identifying the transit dependent populations as a measure of transit demand, calculating the transit supply, and then subtracting the supply from the demand to measure the gap (Jiao and Dillivan, 2013). In detail, transit dependent populations are those who might require transit service to get around more than other people. The transit supply is measured by aggregating a number of criteria that contribute to better transit access within a designated geographic area. Transit deserts are defined as areas where the transit demand is significantly greater than the supply. Compared to previous transit planning methods based on complicated network modeling (Schöbel, 2011; Nayeem et al., 2014; Nikolić and Teodorović, 2013), this research presents a straightforward GIS method to quickly measure the transit demand and supply at the city block group level and professionally presents the results.

Copyright 2017 Junfeng Jiao

http://dx.doi.org/10.5198/jtlu.2017.899

ISSN: 1938-7849 | Licensed under the Creative Commons Attribution - Noncommercial License 3.0

The Journal of Transport and Land Use is the official journal of the World Society for Transport and Land Use (WSTLUR) and is published and sponsored by the University of Minnesota Center for Transportation Studies. 


\section{$1.1 \quad$ Objective}

The main objective of this research was to identify the transit gaps in urban areas of five major Texas cities (Austin, Dallas, Fort Worth, Houston, and San Antonio). Through a clearly defined quantitative analysis of transit supply and demand within the cities (Jiao and Dillivan, 2013), the author was able to highlight areas that might need more attention in regards to transportation access and planning. Using this method, transit agencies and local governments can identify urban neighborhoods in great need of transit service and be able to better locate limited transit resources to the most needed urban areas (Garrett and Taylor, 1999; Polzin et al., 2000).

\subsection{Research methods}

The transit gap analysis was conducted in five major cities of Texas (Austin, Dallas, Fort Worth, Houston, and San Antonio). For each city, transit gaps were measured as the difference between transit supply and demand at the block group level. The transit demand, or the transit dependent population, was calculated using the 2012 American Community Survey. These data were joined with GIS shapefiles from the U.S. Census to spatially display the demand data at the block group level. Transit supply was calculated with data collected directly from the involved municipalities and transit agencies.

A formula created by the U.S. Department of Transportation was used to calculate the transit dependent population at the block group level for each city (Steiss, 2006). First, the household drivers are calculated by subtracting the persons living in group quarters from the population that is 16 years or older. Then, the transit dependent household population is calculated by subtracting the vehicles available from the household drivers and adjusted by the national level carpooling ratio (McKenzie, 2015); see formulas (1), (2) and (3).

Household drivers $=($ population age 16 and over $)-($ persons living in group quarters $)(1)$

Transit-dependent household population $=($ household drivers $)-($ vehicles available $){ }^{*}$ national level carpooling ratio (2)

Transit-dependent population $=($ transit-dependent household population $)+$ (population ages 12-15) + (non-institutionalized population living in group quarters) (3)

Here group quarters and non-institutionalized populations living in group quarters were defined as "a place where people live or stay other than the usual house, apartment, or mobile home. There are institutional group quarters (nursing homes, mental hospitals or wards, hospitals or wards for chronically ill patients, hospices, and prison wards) and noninstitutional group quarters (college or university dormitories, military barracks, group homes, shelters, missions, and flophouses)" (U.S. Census Bureau, 2013).

Census data on vehicles available are not publicly available at the block group level. These data were collected at the census tract level and then proportionally estimated at the block group level based on the size of individual block groups and census tracts. In some block groups, there are more vehicles available than household drivers, thus resulting in a negative value for the transit dependent population. In these cases, the transit dependent population was adjusted to a value of zero, since it would be impossible to have a negative number of people. Once the transit dependent population was calculated for each block group, the value was divided by the acres of each block group to calculate the transit dependent population density per block group. Then Z-scores were calculated for each block group to standardize 
the transit dependent population density in each city.

Transit supply in each city was measured using the following seven criteria (Estupinán and Rodríguez, 2008; Pucher and Buehler, 2009)

1. Number of transit stops within each block group

2. Frequency of transit service within each block group (based on weekday service)

3. Number of transit routes within each block group

4. Total length of sidewalks (miles) in each block group

5. Total length of bike routes (miles) in each block group

6. Total length of low speed limit roads (miles) in each block group

7. Intersection density in each block group

These seven criteria were chosen because together they address both the physical presence of transit as well as the ability to access it. Numerous transit stops and frequent transit services are not effective if it is too difficult to access them. Geospatial data for each of the criteria were spatially joined in GIS with block group shapefiles in each city. Once each of the criteria was measured at the block group level, the value was divided by acres to get the density value and then a z-score value was calculated to standardize each criterion. The z-scores of seven criteria were aggregated to represent the level of transit supply for each block group. Finally, demand and supply $\mathrm{Z}$ scores were subtracted and a final numerical value was calculated for each block group to determine an excess or lack of supply (Hulchanski et al., 2010). Block groups with significantly less supply than demand were shown to have transit gaps and were identified as possible transit deserts (4).

Transit Gap = Supply $(Z$ score $)-$ Demand $(Z$ score $)(4)$

\section{Results}

Houston has the highest transit dependent population percentage $(38.22 \%)$ followed by Dallas (26.19\%), San Antonio (23.74\%), and Fort Worth (22.46\%). Austin is the only city that has less than $20 \%$ transit dependent population (14.70\%) (Table 1$)$.

Table 1: Transit and built environment characteristics of Texas cities

\begin{tabular}{|c|c|c|c|c|c|}
\hline Measurements & Austin & Dallas & Fort Worth & Houston & San Antonio \\
\hline $\begin{array}{l}\text { Population } \\
\text { (2013 estimate, July 2013) }\end{array}$ & 885,400 & $1,257,676$ & 792,727 & $2,195,914$ & $1,409,019$ \\
\hline Transit Dependent Population & $130,146.56$ & $329,386.94$ & $178,058.99$ & $839,284.33$ & $334,529.53$ \\
\hline Percent Transit Dependent & $14.70 \%$ & $26.19 \%$ & $22.46 \%$ & $38.22 \%$ & $23.74 \%$ \\
\hline $\begin{array}{l}\text { Area } \\
\text { [sq. mi.] }\end{array}$ & 297.9 & 340.52 & 339.82 & 599.59 & 460.93 \\
\hline $\begin{array}{l}\text { Density } \\
\text { [pop/sq. mi.] }\end{array}$ & $2,972.14$ & $3,693.40$ & $2,332.79$ & $3,662.36$ & $3,056.90$ \\
\hline Routes & $\begin{array}{r}80 \text { bus } \\
1 \text { rail }\end{array}$ & $\begin{array}{r}113 \text { bus } \\
6 \text { rail }\end{array}$ & $\begin{array}{l}47 \text { bus } \\
1 \text { rail }\end{array}$ & $\begin{array}{r}134 \text { bus } \\
1 \text { rail }\end{array}$ & 111 bus \\
\hline $\begin{array}{l}\text { Stops Within } \\
\text { City Limits }\end{array}$ & 2,620 & 7,653 & 1,977 & 9,182 & 6,810 \\
\hline Average Weekday Ridership & $\begin{array}{r}120,500 \text { bus } \\
2,500 \text { rail }\end{array}$ & $\begin{array}{l}128,511 \text { bus } \\
103,789 \text { rail }\end{array}$ & $\begin{array}{r}25,000 \text { bus } \\
8,000 \text { rail }\end{array}$ & $\begin{array}{r}236,402 \text { bus } \\
42,652 \text { rail }\end{array}$ & 139,335 bus \\
\hline $\begin{array}{l}\text { Trips } \\
\text { (24 hr, weekday) }\end{array}$ & 144,158 & 350,969 & 56,832 & 528,367 & 559,984 \\
\hline $\begin{array}{l}\text { Length, bike routes } \\
\text { [mi] }\end{array}$ & 623.81 & 320.59 & 310.21 & 505.69 & 238.19 \\
\hline $\begin{array}{l}\text { Length, sidewalks } \\
\text { [mi] }\end{array}$ & $2,306.73$ & $6,199.98$ & $2,326.00$ & N/A & 4.777.34 \\
\hline $\begin{array}{l}\text { Length, low-speed roads } \\
\text { [mil] }\end{array}$ & $2,653.93$ & $5,159.37$ & $3,714.45$ & $6,748.78$ & $4,859.63$ \\
\hline Intersections & 19,357 & 65,823 & 26,217 & 61,686 & 47,242 \\
\hline $\begin{array}{l}\text { Intersection density } \\
\text { (intersections/areal }\end{array}$ & 64.98 & 193.30 & 77.15 & 102.88 & 102.49 \\
\hline
\end{tabular}


Houston also operates the largest transit system among these five cities. With one rail line, 134 bus routes, and 9,182 stops, Metropolitan Transit Authority of Harris County (METRO) spreads the service across 600 square miles, which includes 2.2 million residents. METRO has an average weekday ridership of 280,000 , from which $84 \%$ are bus riders and $16 \%$ are rail riders. The city also has the longest low-speed roads (6,748 miles) and the second-longest bike lanes (506 miles) after Austin (624 miles). Dallas has the second largest transit system with 6 rail lines, 113 bus routes, and 7,653 stops within the municipal boundary. On average, it has 230,000 weekday riders, from which $53 \%$ are bus and $47 \%$ are rail riders. It also has the longest sidewalks (6,200 miles) and the second-longest of low-speed roads (5,159 miles) among the five cities. Austin and Fort Worth have comparable populations (885,400 vs. 792,777 ), geographic areas (298 square miles vs. 340 square miles), and similar amounts of sidewalks, low-speed roads, and intersection densities. However, Austin has twice the amount of bike lanes than Fort Worth (624 miles vs. 310 miles). Both systems are made up of bus lines and a single commuter rail line, but the ridership and the number of trips made within a 24-hour period are drastically different $(144,148$ vs. 56,832). Austin's average weekday transit ridership is almost four times higher than that of Fort Worth $(123,000$ vs. 33,000), which suggests Austin residents are more likely to use public transit services than their counterparts in Fort Worth. San Antonio is the only city that does not have rail service out of these five cities, although it has the second largest population $(1,409,019)$, the second largest transit dependent population $(334,529)$, and the highest number of trips made within a 24-hour period.

Table 2: Largest transit gaps in Texas cities

\begin{tabular}{|c|c|c|}
\hline \multicolumn{3}{|l|}{ Largest Gaps } \\
\hline Austin & Neighborhood & Gap \\
\hline 1 & West Campus (25th Street) & -12.90 \\
\hline 2 & West Campus [22nd Street] & -5.87 \\
\hline 3 & West Campus (27th Street) & -5.58 \\
\hline 4 & Pleasant Valley [East Riverside Drive] & -4.84 \\
\hline 5 & West Campus (26th Street and shoal Creek) & -4.78 \\
\hline Dallas & Neighborhood & Gap \\
\hline 1 & Dallas North Tollway \& President George Bush Turnpike & -8.59 \\
\hline 2 & 1635 \& Walnut Hill Lane & -8.32 \\
\hline 3 & Dallas North Tollway \& Lemmon Avenue & -6.02 \\
\hline 4 & Royal Lane \& Skillman Street & -5.73 \\
\hline 5 & Old East Dallas (Bennet Avenue) & -5.59 \\
\hline Fort Worth & Neighborhood & Gap \\
\hline 1 & TCU & -11.63 \\
\hline 2 & Ridgemar (Ridgemar \& |30) & -6.91 \\
\hline 3 & Western Hills (Between Cherry Lane \& Las Vegas Trail) & -5.87 \\
\hline 4 & I30 (Between Oakland Hills Drive \& Country Club Lane) & -5.60 \\
\hline 5 & South Hills (Crowley Road \& Altamesa Boulevard) & -4.92 \\
\hline Houston & Neighborhood & Gap \\
\hline 1 & Sharpstown (Westpark Tollway \& 165) & -12.55 \\
\hline 2 & Chinatown [Westpark Tollway \& Sam Houston Parkway] & -10.37 \\
\hline 3 & $145 \& 1610$ & -8.86 \\
\hline 4 & Gulfton (169 \& Westpark Tollway) & -8.82 \\
\hline 5 & $145 \& 1610$ & -7.86 \\
\hline San Antonio & Neighborhood & Gap \\
\hline 1 & Braun's Farm & -6.44 \\
\hline 2 & 110 \& Wurzbach Road & -6.10 \\
\hline 3 & Hausman Road \& Babcock Road & -5.51 \\
\hline 4 & $1410 \& \mid 10$ & -4.59 \\
\hline 5 & Wurzbach Road \& Evers Road & -3.65 \\
\hline
\end{tabular}


Table 2 shows the top five neighborhoods in each city have the highest levels of transit demand. There is no clear spatial pattern of their spatial distribution. Some block groups are located near downtown (e.g., old East Dallas) or near large universities (e.g., UT-Austin, TCU) (Balsas, 2003) and some are in the newly developed suburban areas (e.g., Sharpstown and Chinatown in Houston, Ridgemar Hall in Fort Worth). Table 3 shows the block groups with the smallest transit gaps within each city. Most of these block groups are located in the downtown areas, where transit demands are relatively well satisfied. Maps of demand, supply, and gaps for each city are shown in Figures 1 through 5; the greater gaps are identified by the darkness of the color. These maps show that Austin and Fort Worth have the fewest transit desert areas, followed by Dallas. However, Houston and San Antonio have more urban areas where the local transit demands are not met by the supplies.

Table 3: Smallest transit gaps in Texas cities

\begin{tabular}{|c|c|c|}
\hline \multicolumn{3}{|l|}{ Smallest Gaps } \\
\hline Austin & Neighborhood & Gap \\
\hline 1 & Downtown & 2.09 \\
\hline 2 & North Campus & 2.04 \\
\hline 3 & UT Campus (Northeast) & 1.65 \\
\hline 4 & Heritage [Between Lamar and Guadalupe] & 1.59 \\
\hline 5 & North Downtown \& Capitol & 1.55 \\
\hline Dallas & Neighborhood & Gap \\
\hline 1 & Downtown & 7.16 \\
\hline 2 & Downtown [East] & 5.18 \\
\hline 3 & Downtown [North] & 4.19 \\
\hline 4 & Downtown (West) & 3.77 \\
\hline 5 & Oak Lawn (North Hall Street) & 3.61 \\
\hline Fort Worth & Neighborhood & Gap \\
\hline 1 & Downtown & 3.72 \\
\hline 2 & Downtown [Panther Island] & 3.63 \\
\hline 3 & Boca Raton Boulevard \& Country Club Lane & 2.36 \\
\hline 4 & Medical district [Rosedale \& Hemphill] & 2.25 \\
\hline 5 & Arlington Heights (Camp Bowie \& Hulen] & 2.15 \\
\hline Houston & Neighborhood & Gap \\
\hline 1 & Downtown on Buffalo Bayou & 7.52 \\
\hline 2 & Downtown [145 and Eastex Freeway] & 7.06 \\
\hline 3 & Midtown & 4.02 \\
\hline 4 & Northeast Downtown & 3.52 \\
\hline 5 & Midtown (Houston Community College) & 3.24 \\
\hline San Antonio & Neighborhood & Gap \\
\hline 1 & Downtown (West Riverwalk] & 7.67 \\
\hline 2 & Downtown [East Riverwalk] & 3.89 \\
\hline 3 & Midtown (San Antonio College) & 2.60 \\
\hline 4 & Fredericksburg Road \& 110 & 2.56 \\
\hline 5 & Midtown [San Pedro Park] & 2.44 \\
\hline
\end{tabular}

\section{Discussion}

Transit deserts were identified in all these five cities. Spatially, these transit desert areas were located in different parts of the city. Austin and Fort Worth have significantly fewer transit deserts than Houston and San Antonio (Figures 1-5). In terms of transit supply, most of these cities have a high concentration of transit service in or near the city center with decreasing services as distance from the center increases (Daganzo, 2010). The areas with high concentrations of supply often extend along major corridors. Transit demand was often scattered sporadically throughout each of the cities. The only consistency for 
transit dependent populations was that they were not located in the central part of the city or downtown. It is not clear whether or not, and to what extent, the supply has an effect on the demand. One way of addressing this problem would be to include more socioeconomic measures to adjust for transit dependent populations (Giuliano, 2005). Further, all five cities have significantly higher proportion of transit demand populations than the transit mode market shares, which indicates that the transit dependent population living outside of a transit system's service area might have to depend on cars and operate them even when it is not economically feasible, purely out of necessity. Local governments need to pay special attentions to these population groups, who are transit dependent but forced to drive, and make sure their transit demands are satisfied within cities.

Figure 1: Transit deserts analysis in Austin, Texas

\section{Austin}

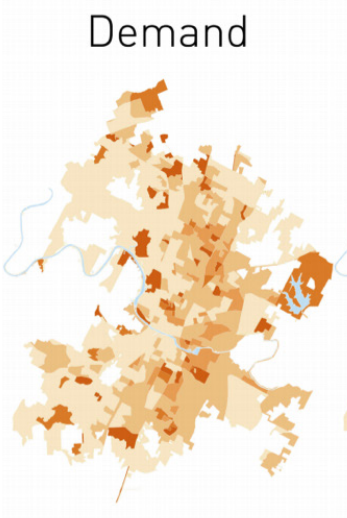

Transit Dependent Population

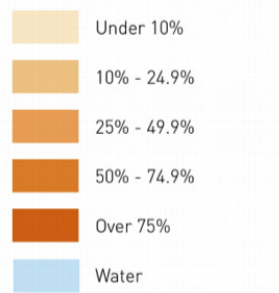

Supply

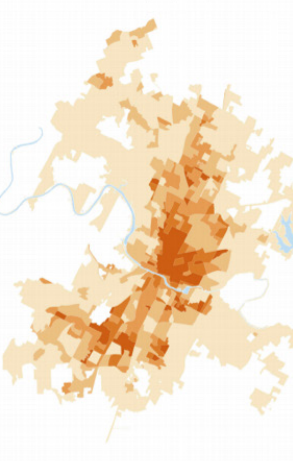

Transit Supply

$-0.59--0.251$

$-0.25--0.01$

$0-0.249$

$0.25-0.249$

$0.5-6.14$

Water
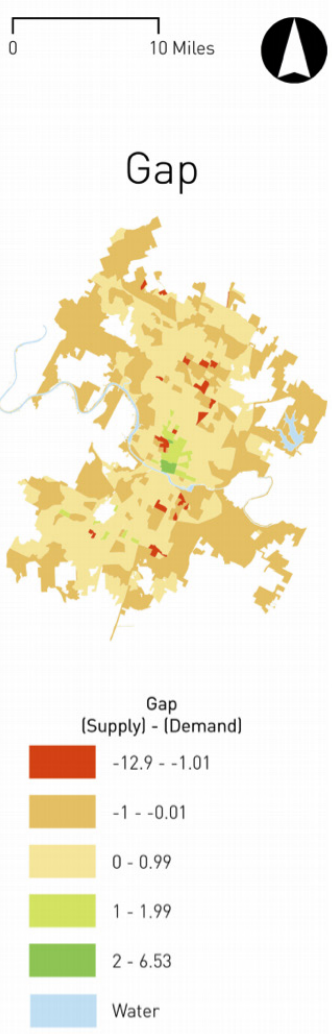
Figure 2: Transit deserts analysis in Dallas, Texas

\section{Dallas}

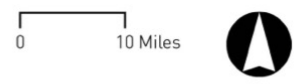

Demand

Supply

Gap
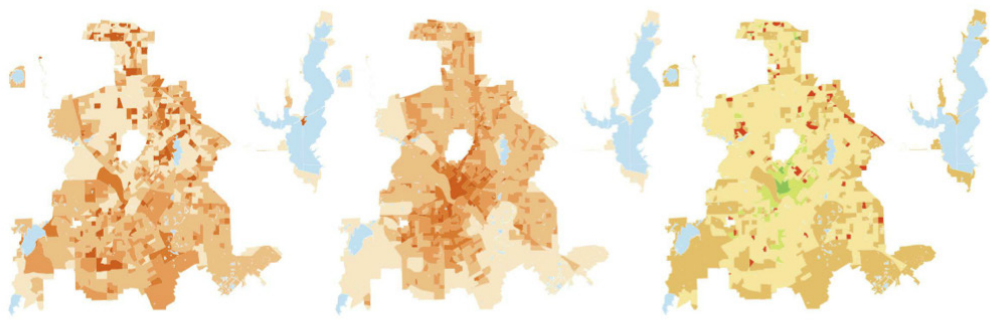

Transit Dependent Population
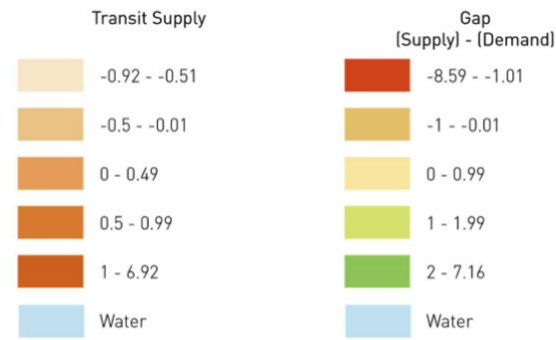

Figure 3: Transit deserts analysis in Fort Worth, Texas

\section{Fort Worth}

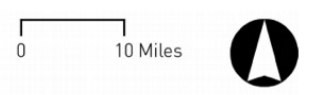

Demand

Supply

Gap
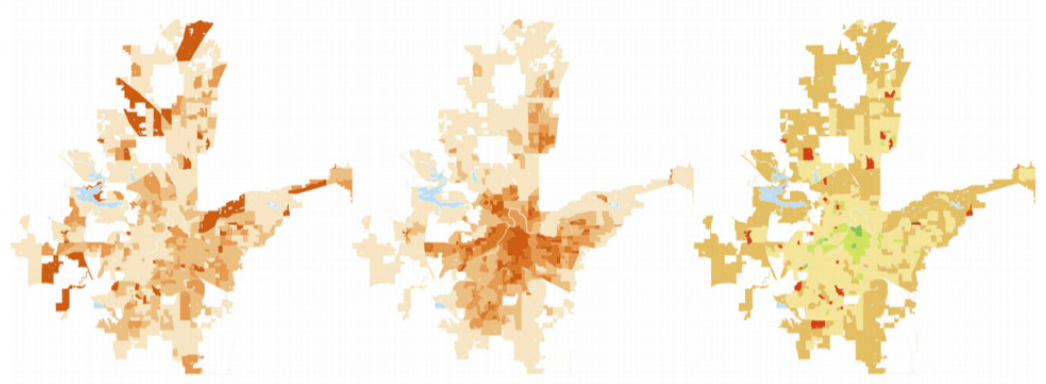

Transit Dependent Population

Transit Supply

Gap
(Supply) - (Demand)
$-11.63--1.01$
$-1--0.01$
$0-0.99$
$1-1.99$
$2-3.72$
Water


Figure 4: Transit deserts analysis in Houston, Texas

\section{Houston}

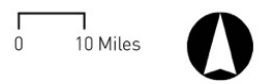

Demand

$$
\text { Supply }
$$

Gap
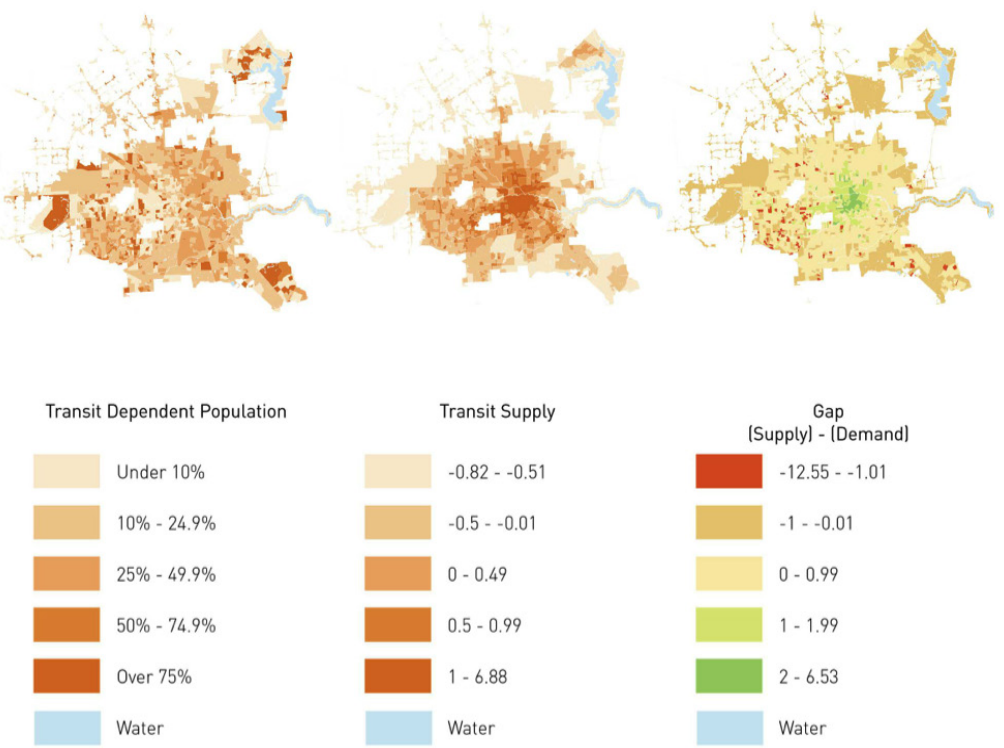

Figure 5: Transit deserts analysis in San Antonio, Texas

\section{San Antonio}

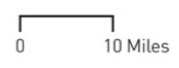

$\boldsymbol{\Delta}$

Demand

Gap
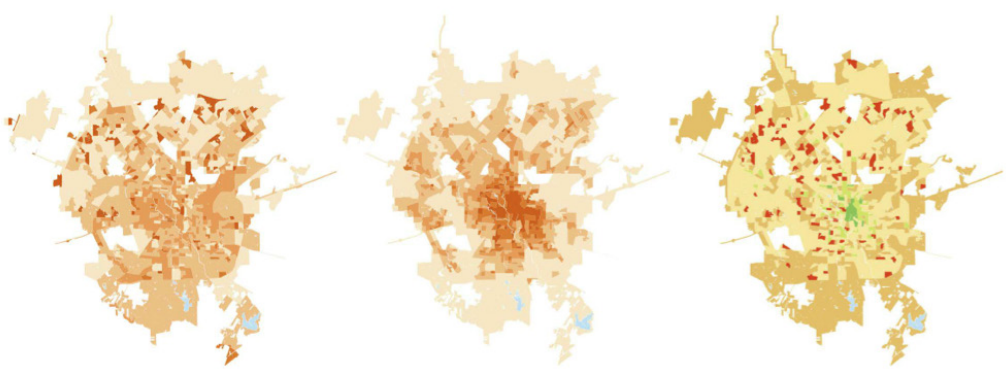

Transit Dependent Population

Transit Supply

\begin{tabular}{|l|l|}
\hline & Under $10 \%$ \\
\hline $10 \%-24.9 \%$ \\
\hline $25 \%-49.9 \%$ \\
\hline $50 \%-74.9 \%$ \\
\hline & Over $75 \%$ \\
\hline Water
\end{tabular}
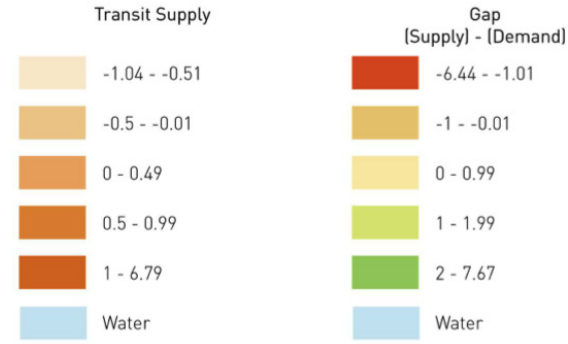
There was no clear grouping of transit deserts identified in Austin. The neighborhoods around the University of Texas at Austin were categorized as transit deserts although these neighborhoods do have a high transit supply compared to the rest of city. The population density and a high concentration of students in these neighborhoods could contribute to the situation. Similar to Austin, Fort Worth also has very few transit deserts identified. Most of the city's transit demand is fairly well served. There are a few block groups with greater demand than supply within the city. Most of these neighborhoods are located in the suburban or rural parts of the city. This may be caused by the lack of adequate sidewalks or bike lanes. In the case of Dallas, the majority of the city is well served with public transit. It has fewer dark colored block groups than other cities. Its 6 rail lines, 119 bus routes, and 7,653 stops are well spread throughout the city. However, there are some transit deserts located near downtown Dallas (e.g., Old East Dallas) and in the northern part of the city. This may be because of the lacking of transit and infrastructure investment in these outskirt areas due to the fast development.

Compared to Austin, Dallas, Fort Worth, Houston and San Antonio have much more transit deserts identified. In the case of Houston, there is a high concentration of transit deserts in the southern part of the city (e.g., Sharpstown and Chinatown), where the median household incomes are lower compared to the rest of the city. San Antonio has the most transit dependent populations but is the only city without rail service. The whole city is relatively under served by transit and has the highest number of transit deserts among the five cities. All these signals indicated a much higher demand for transit services compared to the rest of the four cities.

As a summary, all five cities have higher proportions of transit dependent populations than the transit market shares, which indicates a potential high demand for transit services. Compared to Houston and San Antonio, transit demands are fairly met in Austin, Dallas and Fort Forth. Although there is a fair amount of transit deserts identified in Houston, San Antonio has the strongest demand for transit infrastructure among major Texas cities. Local governance, politics and taxation regimes play major roles in distributing public transportation investments for transit development and improvement. For example, Austin gets its transit funding through a one-cent sales tax, while Fort Worth transit funding comes through only a half-cent sales tax (Hegar, 2016). Thus, in order to remove possible transit deserts, planners need to work with local government officials to develop more transit friendly policies and channel in more investments. This research filled some existing gaps in city level transit optimization by presenting an efficient and approachable method to measure transit demand and supply and transit needs within cities (Klier and Haase, 2015).

\section{$4 \quad$ Conclusions and limitations}

This research demonstrated an effective method to easily quantify transit demand and supply within cities and visually highlights the urban areas where the transit needs are far greater than the transit services. This information can help transportation planners to better plan urban transit systems to serve those who need it most. In an age where transit systems often operate on very limited financial resources, it is extremely important that these systems operate and function as efficiently as possible, serving not only a high number of people, but also highly dependent people, resulting in a more socially just transit system.

While this study has its limitations and can be improved from the following perspectives (e.g., including more socioeconomic and built environment variables for transit demand and supply measures, quantifying transit dependent populations by block group populations, rather than by block group size), it should be noted that the concept of a transit desert and methods used for measuring them are relatively new. This paper might not provide a definitive way of addressing the transit desert problem, but it does act as a step in the right direction. By providing a clear and concise method for measuring transit deserts, this can act as a foundation for future research in the field. The straightforward methods make this research accessible to academics, and most importantly, to the cities and transit agencies that will actually benefit from this research and have the ability to implement changes based on the findings. 


\section{Acknowledgements}

The paper has greatly benefited from the comments of editor Dr. Yingling Fan and the two anonymous reviewers.

The author would like to thank Mr. Aaron Nichols' contribution during the data collection process. 


\section{References}

Balsas, C. J. 2003. Sustainable transportation planning on college campuses. Transport Policy, 10, $35-49$.

Clarke, G., Eyre, H., \& Guy, C. 2002. Deriving indicators of access to food retail provision in British cities: Studies of Cardiff, Leeds and Bradford. Urban Studies, 39, 2041-2060.

Daganzo, C. F. 2010. Structure of competitive transit networks. Transportation Research Part B: Methodological, 44, 434-446.

Estupiñán, N., \& Rodríguez, D. A. 2008. The relationship between urban form and station boardings for Bogota's BRT. Transportation Research Part A: Policy And Practice, 42, 296-306.

Garrett, M., \& Taylor, B. 1999. Reconsidering social equity in public transit. Berkeley Planning Journal, 13.

Giuliano, G. 2005. Low income, public transit, and mobility. Transportation Research Record: Journal of the Transportation Research Board, 63-70.

Hegar, G. 2016. Transit sales and use tax. In Accounts, T. C. O. P. (Ed.). Austin, Texas.

Hulchanski, J. D., Bourne, L. S., \& Egan, R. 2010. The three cities within Toronto: Income polarization among Toronto's neighbourhoods, 1970-2000, Cities Centre, University of Toronto, Toronto.

Jiao, J., \& Dillivan, M. 2013. Transit Deserts: The gap between demand and supply. Journal Of Public Transportation, 16, 2.

Jiao, J., Moudon, A. V., Ulmer, J., Hurvitz, P. M., \& Drewnowski, A. 2012. How to identify food deserts: Measuring physical and economic access to supermarkets in King County, Washington. American Journal of Public Health, 102, E32-E39.

Klier, M. J., \& Haase, K. 2015. Urban public transit network optimization with flexible demand. OR Spectrum, 37, 195-215.

Mckenzie, B. 2015. Who drives to work? Commuting by automobile in the United States: 2013. American Community Survey Reports.

Nayeem, M. A., Rahman, M. K., \& Rahman, M. S. 2014. Transit network design by genetic algorithm with elitism. Transportation Research Part C: Emerging Technologies, 46, 30-45.

Nikolić, M., \& Teodorović, D. 2013. Transit network design by bee colony optimization. Expert Systems with Applications, 40, 5945-5955.

Polzin, S., Chu, X., \& Rey, J. 2000. Density and captivity in public transit success: Observations from the 1995 Nationwide Personal Transportation Study. Transportation Research Record: Journal of The Transportation Research Board, 10-18.

Pucher, J., \& Buehler, R. 2009. Integrating bicycling and public transport in North America. Journal of Public Transportation, 12, 5.

Schöbel, A. 2011. Line planning in public transportation: Models and methods. OR Spectrum, 34, 491-510.

Steiss, T. 2006. Calculating/analyzing transit dependent populations using 2000 census data and GIS. Census Transport.

U.S. Census Bureau. 2013. Population estimates-group quarters and housing unit estimates terms and definitions [Online]. U.S. Census. www.Census.Gov/Popest/About/Terms/Housing.html [Accessed 2016-08-09 2016]

Whelan, A., Wrigley, N., Warm, D., \& Cannings, E. 2002. Life in a food desert. Urban Studies, 39, 2083-2100. 
Wrigley, N. 1993. Retail concentration and the internationalization of British grocery retailing. Retail Change: Contemporary Issues, 41-68.

Wrigley, N., Warm, D., Margetts, B., \& Whelan, A. 2002. Assessing the impact of improved retail access on diet in a food desert: A preliminary report. Urban Studies, 39, 2061-2082. 